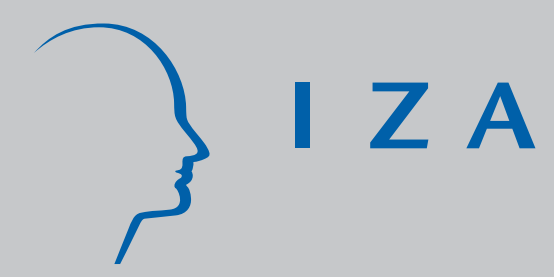

IZADP No. 2559

Rent Taxation in a Small Open Economy:

The Effect on Transitional Generations

Marko Koethenbuerger

Panu Poutvaara

J anuary 2007 


\title{
Rent Taxation in a Small Open Economy: The Effect on Transitional Generations
}

\author{
Marko Koethenbuerger \\ CES, University of Munich and CESifo \\ Panu Poutvaara \\ University of Helsinki and IZA
}
Discussion Paper No. 2559
January 2007

IZA

P.O. Box 7240

53072 Bonn

Germany

Phone: +49-228-3894-0

Fax: +49-228-3894-180

E-mail: iza@iza.org

\begin{abstract}
Any opinions expressed here are those of the author(s) and not those of the institute. Research disseminated by IZA may include views on policy, but the institute itself takes no institutional policy positions.

The Institute for the Study of Labor (IZA) in Bonn is a local and virtual international research center and a place of communication between science, politics and business. IZA is an independent nonprofit company supported by Deutsche Post World Net. The center is associated with the University of Bonn and offers a stimulating research environment through its research networks, research support, and visitors and doctoral programs. IZA engages in (i) original and internationally competitive research in all fields of labor economics, (ii) development of policy concepts, and (iii) dissemination of research results and concepts to the interested public.
\end{abstract}

IZA Discussion Papers often represent preliminary work and are circulated to encourage discussion. Citation of such a paper should account for its provisional character. A revised version may be available directly from the author. 
IZA Discussion Paper No. 2559

January 2007

\section{ABSTRACT}

\section{Rent Taxation in a Small Open Economy: The Effect on Transitional Generations}

We show that taxation of rents may yield an intergenerational Pareto-improvement in a small open economy provided tax revenues are earmarked to reduce wage taxes. Previous literature has shown that rent taxation benefits current young and future generations, while we show that it also benefits the current old generation when the initially prevailing tax mix is sufficiently skewed towards wage taxation.

JEL Classification: H22, E62, F02

Keywords: rent taxes, capitalization, transitional dynamics, labor supply, asset prices

Corresponding author:

Panu Poutvaara

Department of Economics

University of Helsinki

P.O. Box 17 (Arkadiankatu 7)

FIN-00014 Helsinki

Finland

E-mail: panu.poutvaara@helsinki.fi 


\section{Introduction}

Rent taxation influences resource allocation through various channels. Feldstein (1977) shows that a rent tax promotes capital accumulation. The rent tax lowers the price of the fixed factor (e.g. land), which reallocates a higher fraction of savings in the households portfolio choice to the accumulation of physical capital. Consequently, welfare of steady state generations rises. ${ }^{1}$ The effect is of course non-existent in a small open economy in which the household portfolio choice and domestic capital accumulation are disconnected (e.g. Eaton, 1988). As recently shown by Petrucci (2006), rent taxation may still be beneficial in a small open economy provided households endogenously supply labor. For instance, when rent tax revenues are spent on the reduction of distortionary wage taxes, labor supply increases; an effect which is welcomed by steady state generations. They enjoy a lower wage tax without incurring a drop in the price of their land holdings. The latter cost of rent taxation is borne by transitional generations.

This paper analyzes whether the positive effects of rent taxation extend to transitional generations. We show that, provided the initially prevailing level of wage taxes is sufficiently high, introducing rent taxes to reduce wage taxes increases the sum of rental income and land value of the transitional generation. The rationale is that the rise in labor supply raises the marginal productivity of land which capitalizes in the market price of land. As such, earmarking rent tax revenues is helpful in realizing an intergenerational Pareto-improvement. Rent taxation induces a forward intergenerational transfer from transitional generations to steady state generations. The earmarking simultaneously yields a backward, market-based reaction in asset values, which compensates, possibly to a full extent transitional generations.

\footnotetext{
${ }^{1}$ Among others, Calvo et al. (1979), Chamley and Wright (1987) and Ihori (1990) analyze refinements of the effect.
} 


\section{The Model}

Consider a small open economy whose population size is normalized at unity. In any period $t$ production combines three input factors: capital, labor and land. The amount of land is normalized to unity. Labor and capital in the economy in period $t$ are denoted by $L_{t}$ and $K_{t}$, respectively. The production function $Y_{t}=F\left(L_{t}, K_{t}\right)$ exhibits constant returns to scale in all three factors. Capital is internationally mobile. All markets are competitive, and therefore profit maximization implies that:

$$
w_{t}=F_{L_{t}}\left(L_{t}, K_{t}\right), \quad r=F_{K_{t}}\left(L_{t}, K_{t}\right) .
$$

$w_{t}$ denotes the wage rate in period $t$ and $r$ is the exogenous world interest rate. The land rent in period $t, R_{t}$, is given as residual

$$
R_{t}=F\left(L_{t}, K_{t}\right)-F_{L_{t}}\left(L_{t}, K_{t}\right) L_{t}-F_{K_{t}}\left(L_{t}, K_{t}\right) K_{t}
$$

Individuals can invest their savings in the international capital market or the national land market. The economy produces a composite good, which is a perfect substitute for that produced abroad. Rents are taxed at a rate $\tau^{R}<1$. By arbitrage, land value in period $t$, $V_{t}$, is given by

$$
(1+r) V_{t}=\left(1-\tau^{R}\right) R_{t+1}+V_{t+1}
$$

Recursive substitution yields:

$$
V_{t}=\sum_{i=1}^{\infty} \frac{\left(1-\tau^{R}\right) R_{t+i}}{(1+r)^{i}}
$$

We analyze an overlapping generations model in which each cohort lives for two periods. Since each cohort consists of homogenous households, we consider a representative household for each cohort. In the first period of their life individuals born in period $t$ choose their labor supply $l_{t}$ and savings invested in financial assets $s_{t}$ and land acquisition $V_{t}$ from the old generation. In the second period of life, individuals receive the rent payment $R_{t+1}$, sell land to the current young generation and use the receipts along with the deaccumulation 
of financial assets $s_{t}(1+r)$ to finance second-period consumption $c_{t+1}^{2}$. In addition to the rent $\operatorname{tax} \tau^{R}$, the government imposes a tax $\tau^{w}$ on wage income. The first and second period budget constraint thus are

$$
\begin{aligned}
\left(1-\tau^{w}\right) l_{t} w_{t}-c_{t}^{1}-s_{t}-V_{t} & =0 \\
s_{t}(1+r)+\left(1-\tau^{R}\right) R_{t+1}+V_{t+1}-c_{t+1}^{2} & =0 .
\end{aligned}
$$

Household utility is

$$
U\left(1-l_{t}, c_{t}^{1}, c_{t+1}^{2}\right)=c_{t}^{1}+\rho \ln c_{t+1}^{2}-\frac{\gamma}{1+\gamma} l_{t}^{\frac{1+\gamma}{\gamma}} \quad \rho, \gamma>0
$$

Households can save and borrow freely at the exogenous interest rate $r$, determined by the international capital market in order to smoothen their consumption over their lifetime. Labor supply of the young in period $t$ follows from maximizing (7) subject to the budget constraints (5) and (6) which yields

$$
l_{t}=\left(\left(1-\tau^{w}\right) w_{t}\right)^{\gamma}
$$

$d l_{t} / d w_{t}>0$ since income effects on labor supply are absent. The elasticity of labor supply with respect to the net-of-tax wage rate is equal to $\gamma$.

Land price dynamics are captured by (3). Rearranging terms, all "price-dividend" ratios consistent with arbitrage behavior must satisfy

$$
(1+r) \frac{V_{t}}{R_{t}}=\left(1-\tau^{R}\right)+\frac{V_{t+1}}{R_{t+1}}
$$

(8) defines the function $\frac{V_{t+1}}{R_{t+1}}=\phi\left(\frac{V_{t}}{R_{t}}\right)$ with $\phi^{\prime}>1$. Therefore, a steady state $\frac{V_{t}}{R_{t}}=\frac{V_{t+1}}{R_{t+1}}$ exists. Also, the steady state is unique and exhibits point stability. Using (4) the time path of land value is characterized by

$$
V_{t}=\frac{\left(1-\tau^{R}\right) R_{t+1}}{r}
$$

Any change in land value following a tax reform in period $t$ is captured by a jump in land rents in the subsequent period. Finally, we note that the net foreign assets of the economy in 
period $t, F_{t}$, satisfy the transversality condition $\lim _{T \rightarrow \infty}\left(\frac{1}{1+r}\right)^{T} F_{t+T+1}=0$ as each generation's budget constraint is satisfied over its lifetime and $r>0$.

\section{Rent Tax Reform}

We consider a rise in rent taxes at the beginning of period $t$; before the young generation supplies labor and the current elderly sell their land to the young generation. The proceeds are used to reduce the wage tax. The current young cohort and the newly born generations benefit from the tax reform. They are subject to a lower wage tax and trade land at the new steady state price. The current old cohort experiences a change in the value of land holdings. To verify whether it is a gain or loss, we first define labor demand, capital demand and the wage rate as a function of the wage tax. The first-order condition for capital demand defines $L_{t}\left(K_{t}\right)$ and following $(2) R_{t}\left(K_{t}\right)$. Via the first-order condition for labor demand, we get $w_{t}\left(K_{t}\right)$. Inserting $L_{t}\left(K_{t}\right)$ and $w_{t}\left(K_{t}\right)$ into the labor market clearing condition yields $L_{t}\left(K_{t}\right)=l_{t}\left(\left(1-\tau^{w}\right) w_{t}\left(K_{t}\right)\right)$ which defines $K_{t}\left(\tau^{w}\right)$. The slope of the various functions is ${ }^{2}$

$$
\frac{d L_{t}}{d K_{t}}=\frac{-F_{K K}}{F_{K L}}, \frac{d R_{t}}{d K_{t}}=\frac{L_{t} \Delta}{F_{K L}}, \frac{d w_{t}}{d K_{t}}=\frac{-\Delta}{F_{K L}} \quad \text { and } \quad \frac{d K_{t}}{d \tau^{w}}=\frac{w_{t}\left(K_{t}\right) l_{t}^{\prime}}{l_{t}^{\prime}\left(1-\tau^{w}\right) d w_{t} / d K_{t}-d L_{t} / d K_{t}},
$$

where $\Delta:=F_{K K} F_{L L}-F_{K L}^{2}>0$. The public sector budget constraint is $T_{t}=\tau^{w} w_{t} L_{t}+$ $\tau^{R} R_{t}$. Keeping tax revenues constant, tax rates are related as

$$
\left.\frac{d \tau^{w}}{d \tau^{R}}\right|_{d T_{t}=0}=-\frac{\partial T_{t} / \partial \tau^{R}}{\partial T_{t} / \partial \tau^{w}}
$$

with

$$
\frac{\partial T_{t}}{\partial \tau^{R}}=R_{t}>0 \quad \text { and } \quad \frac{\partial T_{t}}{\partial \tau^{w}}=w_{t} L_{t}+\tau^{w} L_{t} \frac{d w_{t}}{d \tau^{w}}+\tau^{w} w_{t} \frac{d L_{t}}{d \tau^{w}}+\tau^{R} \frac{d R_{t}}{d \tau^{w}}
$$

We assume that the economy is on the up-ward sloping part of the tax revenue hill, $\partial T_{t} / \partial \tau^{w}>$ 0 . Using (11), (12) and (9) and invoking stationarity of land rents $\left(R_{t+1}=R_{t}\right)$ we can compute

\footnotetext{
${ }^{2} l_{t}^{\prime}$ denotes the derivative of labor supply with respect to the net-of-tax wage rate $\left(1-\tau^{w}\right) w_{t}$.
} 


$$
\left.\frac{d\left(\left(1-\tau^{R}\right) R_{t}+V_{t}\right)}{d \tau^{R}}\right|_{d T_{t}=0}=-\frac{(1+r) R_{t}}{r}\left(1+\frac{\left(1-\tau^{R}\right) d R_{t} / d \tau^{w}}{\partial T_{t} / \partial \tau^{w}}\right) .
$$

The transition generation benefits from the tax reform if and only if (13) is positive. Resorting to a Cobb-Douglas production function with $\alpha$ and $\beta(\alpha, \beta>0, \alpha+\beta<1)$ being the share of output accruing to labor and capital, we find:

Proposition. Consider an economy in which $\partial T_{t} / \partial \tau^{w}>0$. There always exists an interval of wage tax rates $\left(\underline{\tau}^{w}, \bar{\tau}^{w}\right), \underline{\tau}^{w}<\bar{\tau}^{w}$ and $\underline{\tau}^{w}, \bar{\tau}^{w} \in(0,1)$, in which changing the tax mix from wage to rent taxation improves welfare of the transition generation.

Proof. First, assume $\partial T_{t} / \partial \tau^{w}>0$. Inserting (12) into (13) a necessary and sufficient condition for $d\left(\left(1-\tau^{R}\right) R_{t}+V_{t}\right) /\left.d \tau^{R}\right|_{d T_{t}=0}>0$ is $^{3}$

$$
w_{t} L_{t}+\tau^{w} L_{t} \frac{d w_{t}}{d \tau^{w}}+\tau^{w} w_{t} \frac{d L_{t}}{d \tau^{w}}+\frac{d R_{t}}{d \tau^{w}}<0 .
$$

Using (10) and evaluating the various terms for a Cobb-Douglas production function, (14) holds if and only if

$$
\tau^{w}>\underline{\tau}^{w}:=\frac{1-\beta-(1-\alpha-\beta) \omega}{1-\beta+\omega \alpha}, \quad \omega:=\frac{\gamma(1-\beta)}{1-\beta+\gamma(1-\alpha-\beta)} .
$$

The assumption $\partial T_{t} / \partial \tau^{w}>0$ holds if and only if

$$
\tau^{w}<\bar{\tau}^{w}:=\frac{1-\beta-\tau^{R}(1-\alpha-\beta) \omega}{1-\beta+\omega \alpha} .
$$

Straightforwardly, $\underline{\tau}^{w}<\bar{\tau}^{w}$ as $\tau^{R}<1$. We next prove that $\underline{\tau}^{w}, \bar{\tau}^{w} \in(0,1)$. Observe that by (15) and (16) $\frac{d i}{d \omega} \frac{d \omega}{d \gamma}<0, i=\underline{\tau}^{w}, \bar{\tau}^{w}$. Furthermore, (15) implies $\lim _{\gamma \rightarrow 0} \underline{\tau}^{w}=1$ and $\lim _{\gamma \rightarrow \infty} \underline{\tau}^{w}=0$. Following (16) $\lim _{\gamma \rightarrow 0} \bar{\tau}^{w}=1$ and $\lim _{\gamma \rightarrow \infty} \bar{\tau}^{w}=\frac{\left(1-\tau^{R}\right)(1-\alpha-\beta)}{1-\beta} \in(0,1)$. Thus, $\underline{\tau}^{w}, \bar{\tau}^{w} \in(0,1)$ which completes the proof.

A rent tax lowers the land value and rental income, ceteris paribus. The budget-balancing reduction in labor taxes, however, increases land productivity in the current and future

\footnotetext{
${ }^{3}$ The subsequent proof omits intermediate steps in computing (14), (15) and (16). A detailed proof is in the appendix.
} 
periods. This capitalizes in the land price and may compensate for the negative effect of higher rent taxation, together with the current increase in land rents. In fact, a pre-existing labor $\operatorname{tax} \tau^{w}>\underline{\tau}^{w}$ generates a sufficiently large distortion in the economy (being convex in the tax rate) so as to render the net effect on land value and rental income positive. The tax reform thereby raises welfare of the transition generation and of steady state generations. The upper bound $\bar{\tau}^{w}$ ensures that $\partial T_{t} / \partial \tau^{w}>0$. Straightforwardly, for a level of wage taxes above $\bar{\tau}^{w}$ (and thus $\partial T_{t} / \partial \tau^{w}<0$ ) it is feasible to lower both the wage and rent tax while leaving tax revenues constant. As a result, current and future generations benefit from the reform. To illustrate the scope for intergenerationally welfare-enhancing policies, consider $\left(\alpha, \beta, \gamma, \tau^{R}\right)=(0.6,0.3,0.5,0.1)$. When evaluated subject to the condition $\partial T_{t} / \partial \tau^{w}>0$ the range of wage tax rates which sustain a Pareto-improvement is $\left(\underline{\tau}^{w}, \bar{\tau}^{w}\right)=(0.67,0.71)$. The interval extends to unity in the absence of the condition.

\section{Concluding Remarks}

The paper shows that rent taxation, when combined with a budget-balancing reduction in wage taxes, may also benefit transitional generations. The commonality of interest between transitional generations and steady state generations becomes weaker when considering alternative fiscal uses of rent tax revenues. For instance, a lump-sum transfer of rent tax receipts to steady state generations is still welcome by them (Petrucci, 2006), but eliminates the market based adjustment in land values in the absence of income effects on labor supply and induces a further downward adjustment of land values when leisure is normal in consumption. We leave a rigorous analysis of alternative uses of rent tax revenues to future research.

\section{References}

[1] Calvo, G., Kotlikoff, L., Rodriguez, C., 1979. The incidence of a tax on pure rent: a new (?) reason to an old answer. Journal of Political Economy 87, 869-874. 
[2] Chamley, C., Wright, B., 1987. Fiscal incidence in an overlapping generations model with a fixed asset. Journal of Public Economics 32, 3-24.

[3] Eaton, J., Foreign-owned land. American Economic Review 78, 76-88.

[4] Feldstein, M., 1977. The surprising incidence of a tax on pure rent: a new answer to an old question. Journal of Political Economy 92, 329-333.

[5] Ihori, T., 1990. Economic effects of land taxes in an inflationary economy. Journal of Public Economics 42, 195-211.

[6] Petrucci, A., 2006. The incidence of a tax on pure rent in a small open economy. Journal of Public Economics 90, 921-933.

\section{Appendix}

The appendix contains a detailed proof of the Proposition. For notational simplicity, we omit the time subscript throughout.

Inserting (12) into (13) and invoking stationarity

$$
\begin{aligned}
\left.\frac{d\left(\left(1-\tau^{R}\right) R+V\right)}{d \tau^{R}}\right|_{d T=0} & =-\frac{(1+r) R}{r}\left(1+\frac{\left(1-\tau^{R}\right) \frac{d R}{d \tau^{w}}}{w L+\tau^{w} L \frac{d w}{d \tau^{w}}+\tau^{w} w \frac{d L}{d \tau^{w}}+\tau^{R} \frac{d R}{d \tau^{w}}}\right) \\
& =-\frac{(1+r) R}{r}\left(\frac{w L+\tau^{w} L \frac{d w}{d \tau^{w}}+\tau^{w} w \frac{d L}{d \tau^{w}}+\tau^{R} \frac{d R}{d \tau^{w}}+\left(1-\tau^{R}\right) \frac{d R}{d \tau^{w}}}{w L+\tau^{w} L \frac{d w}{d \tau^{w}}+\tau^{w} w \frac{d L}{d \tau^{w}}+\tau^{R} \frac{d R}{d \tau^{w}}}\right) \\
& =-\frac{(1+r) R}{r}\left(\frac{w L+\tau^{w} L \frac{d w}{d \tau^{w}}+\tau^{w} w \frac{d L}{d \tau^{w}}+\frac{d R}{d \tau^{w}}}{w L+\tau^{w} L \frac{d w}{d \tau^{w}}+\tau^{w} w \frac{d L}{d \tau^{w}}+\tau^{R} \frac{d R}{d \tau^{w}}}\right) .
\end{aligned}
$$

Assuming $\partial T / \partial \tau^{w}=w L+\tau^{w} L \frac{d w}{d \tau^{w}}+\tau^{w} w \frac{d L}{d \tau^{w}}+\tau^{R} \frac{d R}{d \tau^{w}}>0$, a necessary and sufficient condition for (17) to be positive is

$$
w L+\tau^{w} L \frac{d w}{d \tau^{w}}+\tau^{w} w \frac{d L}{d \tau^{w}}+\frac{d R}{d \tau^{w}}<0 .
$$

Using the chain rule the condition reads

$$
w L+\left(\tau^{w} L \frac{d w}{d K}+\tau^{w} w \frac{d L}{d K}+\frac{d R}{d K}\right) \frac{d K}{d \tau^{w}}<0 .
$$


Evaluating the responses $\frac{d i}{d K}, i=w, L, K$ (see (10)) for the Cobb-Douglas production function $Y=L^{\alpha} K^{\beta}$

$$
(18)=\alpha L^{\alpha} K^{\beta}+\left(\tau^{w} w \frac{1-\beta}{\alpha} \frac{L}{K}+\left(1-\tau^{w}\right)(1-\alpha-\beta) L^{\alpha} K^{\beta-1}\right) \frac{d K}{d \tau^{w}}
$$

Inserting $w=\alpha L^{\alpha-1} K^{\beta}$ and collecting terms

$$
(19)=\alpha L^{\alpha} K^{\beta}+\left(\tau^{w}(1-\beta)+\left(1-\tau^{w}\right)(1-\alpha-\beta)\right) L^{\alpha} K^{\beta-1} \frac{d K}{d \tau^{w}} .
$$

Using the first-order condition for capital demand, $r=\beta L^{\alpha} K^{\beta-1}$, to substitute for $K$, and rearranging yields

$$
(20)=\alpha\left(\frac{\beta}{r}\right)^{\frac{\beta}{1-\beta}} L^{\frac{\alpha}{1-\beta}}+\left(1-\alpha-\beta+\tau^{w} \alpha\right)\left(\frac{\beta}{r}\right)^{-1} \frac{d K}{d \tau^{w}} .
$$

We decompose $\frac{d K}{d \tau^{w}}$ into $\frac{d K}{d L} \frac{d L}{d \tau^{w}}$. By the first-order condition $r=\beta L^{\alpha} K^{\beta-1}$ we have

$$
\frac{d K}{d L}=\frac{\alpha}{1-\beta}\left(\frac{\beta}{r}\right)^{\frac{1}{1-\beta}} L^{\frac{\alpha}{1-\beta}-1}
$$

Furthermore, labor supply is $l=\left(\left(1-\tau^{w}\right) w_{t}\right)^{\gamma}$. Substituting $w$ by the first-order condition $w=\alpha L^{\alpha-1} K^{\beta}$ and, subsequently, $K$ by the (inverted) first-order condition $r=\beta L^{\alpha} K^{\beta-1}$,

$$
l=\left(\left(1-\tau^{w}\right) \alpha\left(\frac{\beta}{r}\right)^{\frac{\beta}{1-\beta}} L^{\frac{\alpha}{1-\beta}-1}\right)^{\gamma} .
$$

Setting $l=L$ and solving for $L$ yields

$$
L=\left(\left(1-\tau^{w}\right) \alpha\left(\frac{\beta}{r}\right)^{\frac{\beta}{1-\beta}}\right)^{\omega}, \quad \omega:=\frac{\gamma(1-\beta)}{1-\beta+\gamma(1-\alpha-\beta)} .
$$

Taking the derivative

$$
\begin{aligned}
\frac{d L}{d \tau^{w}} & =-\omega\left(\left(1-\tau^{w}\right) \alpha\left(\frac{\beta}{r}\right)^{\frac{\beta}{1-\beta}}\right)^{\omega-1} \alpha\left(\frac{\beta}{r}\right)^{\frac{\beta}{1-\beta}} \\
& =-\omega \frac{1}{1-\tau^{w}} L .
\end{aligned}
$$

Inserting (22) and (23) into (21) we get 


$$
\begin{aligned}
(21) & =\alpha\left(\frac{\beta}{r}\right)^{\frac{\beta}{1-\beta}} L^{\frac{\alpha}{1-\beta}}-\left(1-\alpha-\beta+\tau^{w} \alpha\right)\left(\frac{\beta}{r}\right)^{-1} \frac{\alpha}{1-\beta}\left(\frac{\beta}{r}\right)^{\frac{1}{1-\beta}} L^{\frac{\alpha}{1-\beta}-1} \omega \frac{1}{1-\tau^{w}} L \\
& =\alpha\left(\frac{\beta}{r}\right)^{\frac{\beta}{1-\beta}} L^{\frac{\alpha}{1-\beta}}-\left(1-\alpha-\beta+\tau^{w} \alpha\right) \frac{\alpha}{1-\beta}\left(\frac{\beta}{r}\right)^{\frac{\beta}{1-\beta}} L^{\frac{\alpha}{1-\beta}} \omega \frac{1}{1-\tau^{w}} \\
& =\alpha\left(\frac{\beta}{r}\right)^{\frac{\beta}{1-\beta}} L^{\frac{\alpha}{1-\beta}}\left(1-\left(1-\alpha-\beta+\tau^{w} \alpha\right) \frac{1}{1-\beta} \omega \frac{1}{1-\tau^{w}}\right) .
\end{aligned}
$$

Recall, provided $\partial T / \partial \tau^{w}>0$ the sum of rental income and land value of the transitional generation increases, $d\left(\left(1-\tau^{R}\right) R_{t}+V_{t}\right) /\left.d \tau^{R}\right|_{d T_{t}=0}>0$, if and only if

$$
1-\left(1-\alpha-\beta+\tau^{w} \alpha\right) \frac{1}{1-\beta} \omega \frac{1}{1-\tau^{w}}<0 .
$$

Equivalently stated,

$$
\tau^{w}>\underline{\tau}^{w}:=\frac{1-\beta-(1-\alpha-\beta) \omega}{1-\beta+\omega \alpha}, \quad \omega:=\frac{\gamma(1-\beta)}{1-\beta+\gamma(1-\alpha-\beta)} .
$$

We next derive the condition under which

$$
\frac{\partial T}{\partial \tau^{w}}=w L+\tau^{w} L \frac{d w}{d \tau^{w}}+\tau^{w} w \frac{d L}{d \tau^{w}}+\tau^{R} \frac{d R}{d \tau^{w}}>0
$$

holds. As can be inferred from (17) the expression is almost congruent to the term $w L+\tau^{w} L \frac{d w}{d \tau^{w}}+\tau^{w} w \frac{d L}{d \tau^{w}}+\frac{d R}{d \tau^{w}}$ which we stepwise rearranged to arrive at (25). Reiterating the same steps, the condition for $\partial T_{t} / \partial \tau^{w}>0$ reads

$$
\tau^{w}<\bar{\tau}^{w}:=\frac{1-\beta-\tau^{R}(1-\alpha-\beta) \omega}{1-\beta+\omega \alpha}, \quad \omega:=\frac{\gamma(1-\beta)}{1-\beta+\gamma(1-\alpha-\beta)} .
$$

Straightforwardly, $\underline{\tau}^{w}<\bar{\tau}^{w}$ when $\tau^{R}<1$. A change in the tax mix from wage to rent taxation increases land value if and only if $\tau^{w} \in\left(\underline{\tau}^{w}, \bar{\tau}^{w}\right)$.

Helpful in proving that $\underline{\tau}^{w}, \bar{\tau}^{w} \in(0,1)$ we first compute the derivative

$$
\begin{aligned}
\frac{d \omega}{d \gamma} & =\frac{(1-\beta)(1-\beta+\gamma(1-\alpha-\beta)-\gamma(1-\alpha-\beta))}{(1-\beta+\gamma(1-\alpha-\beta))^{2}} \\
& =\frac{(1-\beta)^{2}}{(1-\beta+\gamma(1-\alpha-\beta))^{2}}>0 .
\end{aligned}
$$


Turning to the slope of $\underline{\tau}^{w}$ the with respect to $\omega$

$$
\begin{aligned}
\frac{d \underline{\tau}^{w}}{d \omega} & =\frac{-(1-\alpha-\beta)(1-\beta+\omega \alpha)-(1-\beta-(1-\alpha-\beta) \omega) \alpha}{(1-(1-\omega) \alpha)^{2}} \\
& =\frac{-(1-\beta)^{2}}{(1-(1-\omega) \alpha)^{2}}<0 .
\end{aligned}
$$

Similarly,

$$
\begin{aligned}
\frac{d \bar{\tau}^{w}}{d \omega} & =\frac{-\tau^{R}(1-\alpha-\beta)(1-\beta+\omega \alpha)-\left(1-\beta-\tau^{R}(1-\alpha-\beta) \omega\right) \alpha}{(1-(1-\omega) \alpha)^{2}} \\
& =\frac{-(1-\beta)\left(\alpha+\tau^{R}(1-\alpha-\beta)\right)}{(1-(1-\omega) \alpha)^{2}}<0 .
\end{aligned}
$$

Therefore,

$$
\frac{d i}{d \omega} \frac{d \omega}{d \gamma}<0, \quad i=\underline{\tau}^{w}, \bar{\tau}^{w} .
$$

To determine the maximal and minimal value of $\underline{\tau}^{w}$ and $\bar{\tau}^{w}$, we first observe that

$$
\lim _{\gamma \rightarrow 0} \omega=0
$$

and applying L'Hôpital's rule

$$
\lim _{\gamma \rightarrow \infty} \omega=\frac{1-\beta}{1-\alpha-\beta}
$$

Given by (26) and (27)

$$
\lim _{\gamma \rightarrow 0} \underline{\tau}^{w}=1 \quad \text { and } \quad \lim _{\gamma \rightarrow \infty} \underline{\tau}^{w}=0
$$

and

$$
\lim _{\gamma \rightarrow 0} \bar{\tau}^{w}=1 \quad \text { and } \quad \lim _{\gamma \rightarrow \infty} \bar{\tau}^{w}=\frac{\left(1-\tau^{R}\right)(1-\alpha-\beta)}{1-\beta} \in(0,1) .
$$

Thus, $\underline{\tau}^{w}, \bar{\tau}^{w} \in(0,1)$ which completes the proof. 